\title{
Low Risk for Switch to Mania during Treatment with Sleep Promoting Antidepressants
}

Authors

Affiliations

\section{A. Wichniak' ${ }^{1}$, M. Jarkiewicz ${ }^{1}$, Ł. Okruszek ${ }^{2}$, A. Wierzbicka ${ }^{3}$, J. Holka-Pokorska', J. K. Rybakowski ${ }^{4}$}

${ }^{1}$ Third Department of Psychiatry, Institute of Psychiatry and Neurology, Warsaw, Poland ${ }^{2}$ Department of Neuropsychology, Faculty of Psychology, University of Warsaw, Warsaw, Poland ${ }^{3}$ Sleep Disorders Center, Department of Clinical Neurophysiology, Institute of Psychiatry and Neurology, Warsaw, Poland ${ }^{4}$ Department of Adult Psychiatry, Poznan University of Medical Sciences, Poznan, Poland

\author{
Key words \\ - bipolar disorder \\ - switch to mania \\ - antidepressants \\ - trazodone \\ - mirtazapine \\ agomelatine
}

$\begin{array}{lr}\text { received } & 16.10 .2014 \\ \text { revised } & 14.11 .2014 \\ \text { accepted } & 18.11 .2014\end{array}$

Bibliography DOI http://dx.doi.org/ 10.1055/s-0034-1396802 Published online: January 19, 2015 Pharmacopsychiatry 2015; 48: 83-88

(c) Georg Thieme Verlag KG Stuttgart · New York ISSN 0176-3679

Correspondence

A. Wichniak, MD

Institute of Psychiatry and Neurology

Third Department of Psychiatry

Sobieskiego 9

02-957 Warsaw

Poland

wichniak@ipin.edu.pl

\begin{abstract}
$\nabla$

Introduction: Sleep-promoting antidepressants are of interest because they are used not only as antidepressants, but also to promote sleep.

Methods: We reviewed case reports describing the switch to mania during treatment with trazodone, mirtazapine, or agomelatine.

Results: Trazodone, mirtazapine, and agomelatine may induce manic symptoms. However, the risk of switching is related, first of all, to doses recommended for antidepressant treatment, administered without mood-stabilizer co-therapy. Low doses of these antidepressants, used for their hypnotic or sedative effects, were observed
\end{abstract}

\section{Introduction}

\section{$\nabla$}

Antidepressant drugs have been widely prescribed in patients with bipolar disorder, despite clinicians' concern about antidepressant-induced manic switch and the recommendations of practice guidelines. In a recent report on antidepressant use in bipolar disorder, the task force of the International Society of Bipolar Disorders (ISBD) stated that there is striking incongruity between the wide use of antidepressant drugs in bipolar disorder and the weak evidence base for their efficacy and safety. As the frequency and severity of antidepressant-induced manic switch appears to be greater in bipolar I disorder than bipolar II, it is recommended that antidepressants should only be prescribed to bipolar I patients as an adjunct to mood-stabilizing medications [1].

Although the true rate of antidepressant-induced manic switch in bipolar disorder is a controversial issue, there is a consensus that various antidepressants have differing potential for inducing such a switch. Most studies show that such a potential is higher for tricyclic antidepressants (TCAs) and venlafaxine than for selective seroto- to cause mania only in patients with other risk factors for switching. There is no evidence for trazodone or mirtazapine and only sparse evidence for agomelatine, claiming that treatment with these antidepressants is related to an increased risk of switching to mania when administered in combination with a mood stabilizer.

Discussion: These findings suggest that low doses of trazodone and mirtazapine are safe in bipolar disorder, and should still be considered important alternatives to hypnotics when longterm pharmacological treatment of insomnia is necessary. It seems that these antidepressants and agomelatine can also be used safely in antidepressant doses when combined with a mood stabilizer.

nin reuptake inhibitors (SSRIs) and bupropion [2-5].

However, there is sparse evidence concerning the risk of switching with other antidepressants, such as trazodone, mirtazapine, and agomelatine. These 3 drugs are of special interest because they are used in bipolar patients not only for their antidepressant effect, but also to promote sleep [6]. Disturbed sleep is a common problem in patients with bipolar disorder, even in interepisode periods $[7,8]$. For many years, sedative antidepressants were used in such patients as an alternative to benzodiazepine and non-benzodiazepine hypnotics (Z-drugs), because sleep-promoting antidepressants are not related to the risk of hypnotic dependence and can, therefore, be used for a longer time. As the use of antidepressants in bipolar patients has been discouraged in many treatment guidelines, we observe the tendency of these drugs to be replaced by antipsychotics (especially quetiapine), not only in the treatment of bipolar depression, but also as sleep-promoting drugs. Such an approach does not seem to be justified, because evidence for the use of sedative antidepressants in the treatment 
of insomnia is much greater than for sedative antipsychotics. Sedative antidepressants may also be better tolerated [9]. Furthermore, the doses of antidepressants needed to promote sleep are much lower than the doses needed to treat depression [6], so the risk of switching is probably very low.

In this article, we review published case reports describing the switch to mania or hypomania during treatment with trazodone, mirtazapine, or agomelatine, both in monotherapy and in combination with mood stabilizers, and used both in the therapeutic doses for antidepressant effect and in the low doses recommended to promote sleep.

\section{Methods}

$\nabla$

We performed a literature search in PubMed for articles published in the English language, which were published up to September 2014, using the following search terms in the title or abstract: the antidepressant name (trazodone, mirtazapine, agomelatine) AND mania, hypomania, bipolar disorder, or phase shift. To ensure accuracy, the search performed by the first author of this paper was independently repeated by 2 reviewers (M.J., Ł.O.). Furthermore, references of selected papers and relevant review articles were scanned by all authors in order to locate other reports.

\section{Results}

$\nabla$

\section{Trazodone}

Trazodone is an antidepressant of the serotonin antagonist and reuptake inhibitor (SARI) class. Low doses of trazodone (below $150 \mathrm{mg} /$ day) only act via the most potent binding properties, that is, the serotonergic 5HT2A receptors, whereas higher doses recruit additional pharmacological action and result in the blockade of the serotonin transporter (SERT). The ability of trazodone to block SERTs is 100 -fold less potent than its ability to block 5HT2A receptors. As both of these actions are considered necessary for an antidepressant effect, the trazodone dose recommended for the treatment of depression is usually above $150 \mathrm{mg} /$ day [10], whereas low doses (25-150 mg/day) are usually sufficient for sleep-promoting effects [6].

The development of switch to mania or hypomania associated with trazodone treatment was described in 17 patients ( $\odot$ Table 1 ).

9 of those patients were treated in monotherapy with the antidepressant dose ( $\geq 150 \mathrm{mg} /$ day) of trazodone [11-18]. In only 4 cases, monotherapy with a low dose of trazodone ( $100 \mathrm{mg} /$ day) was found to be associated with switch to mania or hypomania $[11,13,14]$. All of these 4 cases were older patients (over 60 years old), so they could have a slower elimination rate and, therefore, higher trazodone plasma concentrations compared to the younger patients. Furthermore, in 3 of those 4 patients, other factors were present that could increase the risk of switch to mania. 2 patients were treated with other antidepressants before the start of the trazodone treatment, and one patient obtained trazodone treatment during detoxification from benzodiazepines. In only 2 patients, a very low dose of trazodone ( $50 \mathrm{mg} /$ day) was described as being related to switch to mania or a mixed depressive state. In both cases, treatment with trazodone was combined with other antidepressants, and in one patient additionally with a non-pharmacological intervention (continuous positive airway pressure, CPAP) [19,20] A non- pharmacological intervention (repetitive transcranial magnetic stimulation, rTMS) added to combined treatment with trazodone (200 mg/day), paroxetine, opipramol, amitriptyline, prazepam and methadone induced a depressive mixed episode in a further patient [21]. In one patient, a switch to hypomania was observed 3 weeks after the discontinuation of trazodone treatment [16]. Additionally, in 2 depressed patients with probable bipolar disorder, who did not respond to trazodone, a switch to mania was described after trazodone was abruptly replaced with imipramine [22]. There are no published cases describing a switch to mania or hypomania in patients who were treated with a mood stabilizer and trazodone as an antidepressant or a sleep-promoting treatment.

The average time until the onset of mania/hypomania after the start of treatment with trazodone was 14.7 days (median 7 days). 9 patients were described as switching to mania, 6 to hypomania, one to hypomania followed by a mixed episode, and one to a mixed depressive episode.

\section{Mirtazapine}

Mirtazapine is a noradrenergic and specific serotonergic antidepressant (NaSSA). Its mechanism of action involves noradrenergic alpha2-auto- and hetero-receptor blockade, enhancing noradrenaline (NE) and serotonin (5-HT) release, as well as blockade of serotonergic 5-HT2 and 5-HT3 and histaminergic $\mathrm{H} 1$ receptors [23]. The recommended dose of mirtazapine for the treatment of depression is $30-45 \mathrm{mg} /$ day because, in this dose range, mirtazapine acts as an alpha2 antagonist and a 5-HT and NE disinhibitor. However, for the sleep-promoting effect, only the antagonistic action of mirtazapine on histaminergic $\mathrm{H} 1$ receptors is necessary. For this effect, low doses of mirtazapine of $3.75-15 \mathrm{mg} /$ day are usually sufficient [6].

Development of a switch to mania or hypomania associated with mirtazapine treatment was described in 10 patients (० Table 2).

3 of those patients were treated in monotherapy with the antidepressant dose ( $\geq 30 \mathrm{mg} /$ day) of mirtazapine [24-26]. One of those patients may have been at higher risk of switching, because she was an older patient and the treatment with mirtazapine was started without a period of washout from fluoxetine $(20 \mathrm{mg} /$ day) [26]. In 2 further patients, treatment with antidepressant dose of mirtazapine was combined with treatment using SSRIs $[27,28]$. In one patient hypomania was observed after a dose of mirtazapine was increased to $60 \mathrm{mg} /$ day [29]. Mirtazapine doses lower than $30 \mathrm{mg} /$ day were found to be associated with switch to mania or hypomania in only 3 cases [30-32]. In the first of those patients, mirtazapine $(15 \mathrm{mg} /$ day) was added to a high dose $(250 \mathrm{mg} /$ day $)$ of sertraline [32]. The second patient was an older patient, a 68-year-old woman with organic, post-stroke depression [30], and the third patient was a young patient, a 15-year-old girl [31]. In one older depressed patient, a switch to hypomania was observed 2 days after mirtazapine discontinuation, following 35 days of treatment [33]. There are no published cases that describe a switch to mania or hypomania in patients who were treated with a mood stabilizer and mirtazapine either in antidepressant or in a sleep-promoting dose.

The average time until the onset of mania/hypomania after the start of the treatment or a dose increase of mirtazapine was 15.7 days (median 7 days). 5 patients were described as switching to mania, 4 to hypomania, and one to a mixed depressive episode. 

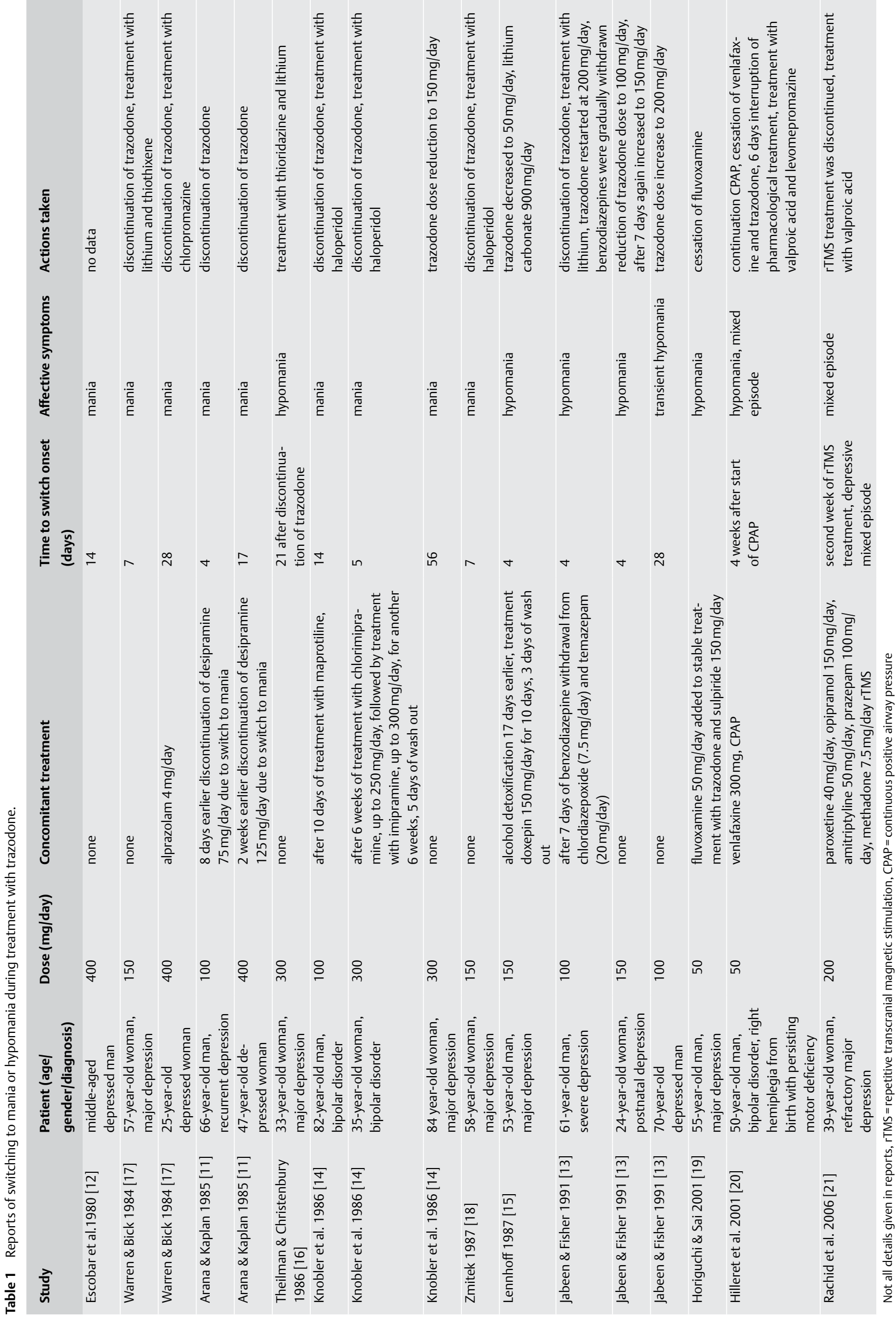
Table 2 Reports of switching to mania or hypomania during treatment with mirtazapine.

\begin{tabular}{|c|c|c|c|c|c|c|}
\hline Study & $\begin{array}{l}\text { Patient (age/ } \\
\text { gender/diagnosis) }\end{array}$ & $\begin{array}{l}\text { Dose } \\
\text { (mg/day) }\end{array}$ & $\begin{array}{l}\text { Concomitant } \\
\text { treatment }\end{array}$ & $\begin{array}{l}\text { Time to switch } \\
\text { onset (days) }\end{array}$ & $\begin{array}{l}\text { Affective } \\
\text { symptoms }\end{array}$ & Actions taken \\
\hline $\begin{array}{l}\text { Soutullo et al. } \\
1998[32]\end{array}$ & $\begin{array}{l}\text { 45-year-old, } \\
\text { woman, MDE }\end{array}$ & 15 & sertraline $250 \mathrm{mg} /$ day & 4 & hypomania & $\begin{array}{l}\text { discontinuation of } \\
\text { mirtazapine }\end{array}$ \\
\hline $\begin{array}{l}\text { De Leon et al., } \\
1999[30]\end{array}$ & $\begin{array}{l}\text { 68-year-old, man, } \\
\text { poststroke } \\
\text { depression }\end{array}$ & 15 & $\begin{array}{l}\text { after } 10 \text { days of wash } \\
\text { out from paroxetine } \\
60 \mathrm{mg} / \text { day }\end{array}$ & 3 & hypomania & $\begin{array}{l}\text { mirtazapine was discontin- } \\
\text { ued, treatment with carba- } \\
\text { mazepine and haloperidol }\end{array}$ \\
\hline $\begin{array}{l}\text { MacCall \& } \\
\text { Callender } 1999 \\
\text { [33] }\end{array}$ & $\begin{array}{l}65 \text {-year-old, } \\
\text { woman, MDE }\end{array}$ & 30 & none & $\begin{array}{l}\text { 2, after mirtazapine } \\
\text { discontinuation after } \\
35 \text { days of treatment }\end{array}$ & hypomania & $\begin{array}{l}\text { symptoms remitted after } \\
6 \text { weeks }\end{array}$ \\
\hline $\begin{array}{l}\text { Bhanji et al. } 2002 \\
\text { [29] }\end{array}$ & $\begin{array}{l}\text { 43-year-old woman, } \\
\text { MDE }\end{array}$ & 60 & $\begin{array}{l}\text { after washout form } \\
\text { venlafaxine } 225 \mathrm{mg} / \\
\text { day, topiramate } \\
400 \mathrm{mg} / \text { day }\end{array}$ & $\begin{array}{l}7 \text {, after dose increase } \\
\text { to } 60 \mathrm{mg} / \text { day }\end{array}$ & mania & $\begin{array}{l}\text { mirtazapine dose reduced } \\
\text { to } 45 \mathrm{mg} / \text { day, lithium } \\
\text { carbonate } 600 \mathrm{mg} / \text { day, } \\
\text { topiramate } 400 \mathrm{mg} / \text { day }\end{array}$ \\
\hline $\mathrm{Ng} 2002$ [27] & $\begin{array}{l}\text { 48-year-old } \\
\text { depressed woman }\end{array}$ & 30 & $\begin{array}{l}\text { fluoxetine } 40 \text { mg/day, } \\
\text { alprazolam } 1 \text { mg/day }\end{array}$ & 35 & mania & $\begin{array}{l}\text { discontinuation of } \\
\text { fluoxetine, dose mirtazap- } \\
\text { ine reduced to } 15 \mathrm{mg} / \\
\text { day and discontinued, } \\
\text { valproate } 2000 \mathrm{mg} / \text { day and } \\
\text { clonazepam } 0.5 \mathrm{mg} / \text { day at } \\
\text { bedtime }\end{array}$ \\
\hline $\begin{array}{l}\text { Prost \& Abraham } \\
2004[28]\end{array}$ & $\begin{array}{l}\text { 35-year-old woman, } \\
\text { major depression }\end{array}$ & 45 & paroxetine $50 \mathrm{mg} /$ day & 56 & hypomania & mirtazapine discontinued \\
\hline $\begin{array}{l}\text { Goyal \& Sinha } \\
2008[31]\end{array}$ & $\begin{array}{l}\text { 15-year-old girl, } \\
\text { severe depressive } \\
\text { episode }\end{array}$ & 22.5 & none & 14 & mania & $\begin{array}{l}\text { lithium } 900 \mathrm{mg} / \text { day after } \\
\text { discontinuing mirtazapine, } \\
\text { haloperidiol } 5 \mathrm{mg} / \text { day }\end{array}$ \\
\hline $\begin{array}{l}\text { Liu et al. } 2009 \\
\text { [26] }\end{array}$ & $\begin{array}{l}\text { 66-year-old women } \\
\text { with late life } \\
\text { depression }\end{array}$ & 30 & $\begin{array}{l}\text { switch from fluox- } \\
\text { etine } 20 \mathrm{mg} / \text { day } \\
\text { without a period of } \\
\text { tapering-off, washout } \\
\text { or cross-titration }\end{array}$ & 3 & mania & $\begin{array}{l}\text { mirtazapine discontinued, } \\
\text { treatment with valproate } \\
\text { and low-dose risperidone }\end{array}$ \\
\hline $\begin{array}{l}\text { Habermeyer et al. } \\
2010 \text { [25] }\end{array}$ & $\begin{array}{l}\text { 51-year-old patient, } \\
\text { major depression }\end{array}$ & 45 & none & $\begin{array}{l}5 \text { after dose increase } \\
\text { to } 45 \mathrm{mg} / \text { day }\end{array}$ & $\begin{array}{l}\text { mixed } \\
\text { episode }\end{array}$ & $\begin{array}{l}\text { mirtazapine discontinued, } \\
\text { treatment with olanzapine } \\
\text { and lithium }\end{array}$ \\
\hline $\begin{array}{l}\text { Basavraj et al. } \\
2011[24]\end{array}$ & $\begin{array}{l}\text { 42-year-old woman, } \\
\text { recurrent depressive } \\
\text { disorder }\end{array}$ & 30 & $\begin{array}{l}\text { after tapering down } \\
\text { escitalopram } 20 \mathrm{mg} / \\
\text { day }\end{array}$ & 14 & mania & $\begin{array}{l}\text { discontinuation of mir- } \\
\text { tazapine, treatment with } \\
\text { lithium } 900 \mathrm{mg} / \text { day, } \\
\text { quetiapine } 100 \mathrm{mg} / \text { day }\end{array}$ \\
\hline
\end{tabular}

MDE - major depressive episode

\section{Agomelatine}

Agomelatine is an antidepressant with a novel non-monoaminergic mechanism of action. It is a melatonin agonist at both melatonin receptors MT1 and MT2 and a serotonin antagonist at 5 -HT2C receptors. The recommended dose of agomelatine to treat depression is $25-50 \mathrm{mg} /$ day [34]. So far, it is unknown whether lower doses of agomelatine can be used to have only a sleep-promoting effect.

Recently, a switch to hypomania has been described in a 52-yearold female patient with the diagnosis of a recurrent major depressive disorder and comorbid panic disorder. The patient was treated with paroxetine $20 \mathrm{mg} / \mathrm{day}$ and trazodone $100 \mathrm{mg} /$ day. As no improvement was observed after 1 month, the patient was admitted to hospital and the paroxetine treatment was shifted to agomelatine $25 \mathrm{mg} /$ day, while $100 \mathrm{mg}$ /day trazodone was maintained. After 4 days, the symptoms of hypomania occurred, and the agomelatine was discontinued 2 days later. One week after stopping the agomelatine treatment, the hypomanic symptoms remitted [35]. In a study that evaluated the efficacy of agomelatine in patients with bipolar I disorder, who were experiencing a major depressive episode during treatment with lithium or valpromide, there were 3 of 13 agomelatine and lithium treated patients who experienced manic or hypomanic episodes during an optional observation period of up to 46 weeks Only one of those cases was rated as treatment-related [36].

\section{Discussion}

The described cases suggest that trazodone, mirtazapine, and agomelatine may induce manic symptoms in some patients. It happens most frequently at an early stage of treatment, which has been already noticed before [37]. The risk of a switch to mania or hypomania during treatment with trazodone or mirtazapine seems to be related, first of all, to the doses recommended for antidepressant treatment, administered without concomitant mood-stabilizer therapy. Low doses of these antidepressants, which can be used for their hypnotic or sedative effects, were observed to cause a switch to mania or hypomania only in patients with other risk factors for switching, such as treatment with other antidepressants, organic origin of the depressive symptoms, and being of an older or very young age. There is no evidence for trazodone and mirtazapine, and only sparse evidence for agomelatine [36], claiming that treatment with these antidepressants is related to an increased risk of 
switch to mania when administered in combination with a mood stabilizer. This last finding of our review is supported by results of a recent study based on Swedish national registries, which examined the risk of antidepressant-induced manic switch in patients with bipolar disorder who were being treated either with antidepressant monotherapy or with an antidepressant in conjunction with a mood stabilizer. Although an increased risk of manic switch was found among patients with bipolar disorder on antidepressant monotherapy, the risk of manic episodes was not increased in the short or long term for patients treated with an antidepressant and a concurrent mood stabilizer [38].

To interpret the findings from the case reports reviewed by us, we have to take into account that switching to mania or hypomania related to treatment with trazodone, mirtazapine, or agomelatine may be more common, but underreported. The reason may be, for example, the relatively mild intensity of the hypomanic symptoms. In many described case reports, the described symptoms did not require any other action than stopping or reducing the dose of the administered antidepressant. Some authors even claimed that, in their experience, trazodoneinduced hypomanic symptoms may be transient and that immediate withdrawal of trazodone may not always be necessary [13]. In some cases, switching to mania or hypomania may also be considered as resulting from illness progression [39] or stressful life events [40].

However, at least for mirtazapine, the low risk of a switch to mania was also found in studies that analyzed data from clinical trials. In a review of the initial clinical trials, manic symptoms associated with mirtazapine treatment were described in 3 $(0.25 \%)$ of 1299 patients [41]. In a study that analyzed data from 2 clinical trials in patients with rapid-cycling bipolar disorder, the rate of treatment-derived mania/hypomania was $30.1 \%$ for SSRIs (highest for fluoxetine $42.1 \%$, lowest for fluvoxamine $0 \%$ ), $35.7 \%$ for bupropion, $30.6 \%$ for venlafaxine, $18.8 \%$ for nefazodone (a drug with similar pharmacological action to trazodone), and there were no cases of switching observed for mirtazapine [42].

All of these data suggest that low doses of trazodone and mirtazapine are safe in patients with bipolar disorder and should still be considered as important alternatives to hypnotics when long-term pharmacological treatment of insomnia is necessary. We believe that such a use of sleep-promoting antidepressants can even decrease the risk of switching, because the effective treatment of insomnia in bipolar patients improves the course of the disorder and quality of life. It also seems that trazodone, mirtazapine, and agomelatine can be used safely in antidepressant doses when combined with a mood stabilizer, especially in patients with bipolar II disorder.

Further work should clarify whether doxepin, the only sedative antidepressant approved by the FDA for the treatment of insomnia characterized by difficulty with sleep maintenance, can also be used to treat insomnia in bipolar disorder. Although TCAs are regarded as antidepressants with the highest risk of a switch to mania [43], there is no evidence to claim that low doses (3 and $6 \mathrm{mg}$ ) of doxepin, which show only antihistaminergic effects $[6,44]$, are related to treatment-emergent mania or hypomania. Another interesting tricyclic antidepressant worthy of consideration as sleep-promoting drug is trimipramine. Trimipramine is regarded as an atypical antidepressant with antipsychotic and sedative properties. It has been studied in monotherapy in delusional depression [45] and in low dose to treat primary insomnia
[46]. In some countries it is frequently used to induce sleep, also as adjuvant therapy to other drugs [47].

It is also noteworthy that the sleep-promoting effect may not be the most relevant feature for estimating the switch risk and choice of an antidepressant. In patients with bipolar disorder without sleep problems a dopaminergic antidepressant bupropion may be a reasonable first-line treatment. Bupropion has lower rates of manic switch than tricyclic and tetracyclic antidepressants and norepinephrine-serotonin reuptake inhibitors [1] and is especially useful, e.g., in bipolar disorder comorbid with attention-deficit/hyperactivity disorder [48].

\section{Conflict of Interest \\ $\nabla$}

During last 3 years Adam Wichniak has received speaker honoraria and consultancies, congress and educational grants from Angelini, Lundbeck, Servier. Janusz K. Rybakowski has participated in advisory boards for AstraZeneca, Bristol-Myers Squibb, Eli Lilly, and Sanofi-Aventis and has lectured for Janssen-Cilag, Lundbeck, and Servier.

\section{References}

1 Pacchiarotti I, Bond DJ, Baldessarini RJ et al. The International Society for Bipolar Disorders (ISBD) task force report on antidepressant use in bipolar disorders. Am J Psychiatry 2013; 170: 1249-1262

2 Post RM, Altshuler LL, Leverich GS et al. Mood switch in bipolar depression: comparison of adjunctive venlafaxine, bupropion and sertraline. Br J Psychiatry 2006; 189: 124-131

3 Sachs GS, Lafer B, Stoll AL et al. A double-blind trial of bupropion versus desipramine for bipolar depression. J Clin Psychiatry 1994; 55: 391-393

4 Rybakowski JK, Koszewska I, Puzynski S. Anticholinergic mechanisms: a forgotten cause of the switch process in bipolar disorder. J Clin Psychiatry 2010; 71: 1698-1699

5 Koszewska I, Rybakowski JK. Antidepressant-induced mood conversions in bipolar disorder: a retrospective study of tricyclic versus nontricyclic antidepressant drugs. Neuropsychobiology 2009; 59: 12-16

6 Wichniak A, Wierzbicka A, Jernajczyk W. Sleep and antidepressant treatment. Curr Pharm Des 2012; 18: 5802-5817

$7 \mathrm{Ng} \mathrm{TH}$, Chung KF, Ho FY et al. Sleep-wake disturbance in interepisode bipolar disorder and high-risk individuals: A systematic review and meta-analysis. Sleep Med Rev 2014

8 Wichniak A, Wierzbicka A, Jernajczyk W. Sleep as a biomarker for depression. Int Rev Psychiatry 2013; 25: 632-645

9 Wilson SJ, Nutt DJ, Alford C et al. British Association for Psychopharmacology consensus statement on evidence-based treatment of insomnia, parasomnias and circadian rhythm disorders. J Psychopharmacol 2010; 24: 1577-1601

10 Stahl SM. Mechanism of action of trazodone: a multifunctional drug. CNS Spectr 2009; 14: 536-546

11 Arana GW, Kaplan GB. Trazodone-induced mania following desipramine-induced mania in major depressive disorders. Am J Psychiatry 1985; 142: 386

12 Escobar JI, Gomez J, Constain C et al. Controlled clinical trial with trazodone, a novel antidepressant. A South American experience. J Clin Pharmacol 1980; 20: 124-130

13 Jabeen S, Fisher CJ. Trazodone-induced transient hypomanic symptoms and their management. Br J Psychiatry 1991; 158: 275-278

14 Knobler HY, Itzchaky S, Emanuel $\mathrm{D}$ et al. Trazodone-induced mania. $\mathrm{Br}$ J Psychiatry 1986; 149: 787-789

15 Lennhoff M. Trazodone-induced mania. J Clin Psychiatry 1987; 48: 423-424

16 Theilman SB, Christenbury MM. Hypomania following withdrawal of trazodone. Am J Psychiatry 1986; 143: 1482-1483

17 Warren M, Bick PA. Two case reports of trazodone-induced mania. Am J Psychiatry 1984; 141: 1103-1104

18 Zmitek A. Trazodone-induced mania. Br J Psychiatry 1987; 151: $274-$ 275

19 Horiguchi T, Sai S. A display of hypomania in a depressed male in response to fluvoxamine. World J Biol Psychiatry 2001; 2: 201-204 
20 Hilleret $H$, Jeunet $E$, Osiek $C$ et al. Mania resulting from continuous positive airways pressure in a depressed man with sleep apnea syndrome. Neuropsychobiology 2001; 43: 221-224

21 Rachid F, Golaz J, Bondolfi $G$ et al. Induction of a mixed depressive episode during rTMS treatment in a patient with refractory major depression. World J Biol Psychiatry 2006; 7: 261-264

22 Haggerty JJ Jr, Jackson R. Mania following change from trazodone to imipramine. J Clin Psychopharmacol 1985; 5: 342-343

23 de Boer $T$. The effects of mirtazapine on central noradrenergic and serotonergic neurotransmission. Int Clin Psychopharmacol 1995; 10 (Suppl 4): 19-23

24 Basavraj V, Nanjundappa GB, Chandra PS. Mirtazapine induced mania in a woman with major depression in the absence of features of bipolarity. Aust N Z J Psychiatry 2011; 45: 901

25 Habermeyer B, Bayer U, Muller-Spahn F. Mania associated with mirtazepine treatment and mixed depression. Pharmacopsychiatry 2010; 43: $37-38$

26 Liu CC, Liang KY, Liao SC. Antidepressant-associated mania: soon after switch from fluoxetine to mirtazapine in an elderly woman with mixed depressive features. J Psychopharmacol 2009; 23: 220-222

$27 \mathrm{Ng} \mathrm{B}$. Mania associated with mirtazapine augmentation of fluoxetine. Depress Anxiety 2002; 15: 46-47

28 Prost E, Abraham G. Mirtazapine-induced shopping spree. Can J Psychiatry 2004; 49: 495

29 Bhanji NH, Margolese HC, Saint-Laurent $M$ et al. Dysphoric mania induced by high-dose mirtazapine: a case for 'norepinephrine syndrome'? Int Clin Psychopharmacol 2002; 17: 319-322

30 De Leon OA, Furmaga KM, Kaltsounis J. Mirtazapine-induced mania in a case of poststroke depression. J Neuropsychiatry Clin Neurosci 1999; 11: 115-116

31 Goyal N, Sinha VK. Mirtazapine-induced manic switch in adolescent unipolar depression. Aust N Z J Psychiatry 2008; 42: 1070-1071

32 Soutullo CA, McElroy SL, Keck PE Jr. Hypomania associated with mirtazapine augmentation of sertraline. J Clin Psychiatry 1998; 59: 320

33 MacCall C, Callender J. Mirtazapine withdrawal causing hypomania. Br J Psychiatry 1999; 175: 390

34 Hickie IB, Rogers NL. Novel melatonin-based therapies: potential advances in the treatment of major depression. Lancet 2011; 378 : 621-631

$35 \mathrm{Tu}$ KY, Lin PY. Hypomania soon after shifting from paroxetine to agomelatine in a middle-aged woman with depression. Clin Neuropharmacol 2014; 37: 82-83
36 Calabrese J, Guelfi JD, Perdrizet-Chevallier C. Agomelatine adjunctive therapy for acute bipolar depression: preliminary open data. Bipolar Disord 2007; 9: 628-635

37 Terao $T$. Comparison of manic switch onset during fluoxetine and trazodone treatment. Biol Psychiatry 1993; 33: 477-478

38 Viktorin A, Lichtenstein $P$, Thase ME et al. The risk of switch to mania in patients with bipolar disorder during treatment with an antidepressant alone and in combination with a mood stabilizer. Am J Psychiatry 2014; 171: 1067-1073

39 Rodrigues $A A$, Rosa AR, Kunz $M$ et al. Bipolar disorder: staging and neuroprogression. Psychiatr Pol 2014; 48: 231-243

40 Kasprzak M, Kiejna A. Research on the role of life events in bipolar disorder. Psychiatr Pol 2013; 47: 875-885

41 Montgomery SA. Safety of mirtazapine: a review. Int Clin Psychopharmacol 1995; 10 (Suppl 4): 37-45

42 Gao K, Kemp DE, Ganocy SJ et al. Treatment-emergent mania/hypomania during antidepressant monotherapy in patients with rapid cycling bipolar disorder. Bipolar Disord 2008; 10: 907-915

43 Sidor MM, MacQueen GM. An update on antidepressant use in bipolar depression. Curr Psychiatry Rep 2012; 14: 696-704

44 Stahl SM. Enhancing outcomes from major depression: using antidepressant combination therapies with multifunctional pharmacologic mechanisms from the initiation of treatment. CNS Spectr 2010; 15: 79-94

45 Kunzel HE, Ackl N, Hatzinger $M$ et al. Outcome in delusional depression comparing trimipramine monotherapy with a combination of amitriptyline and haloperidol - a double-blind multicenter trial. J Psychiatr Res 2009; 43: 702-710

46 Riemann $D$, Voderholzer $U$, Cohrs $S$ et al. Trimipramine in primary insomnia: results of a polysomnographic double-blind controlled study. Pharmacopsychiatry 2002; 35: 165-174

47 Wiegand $M H$. Antidepressants for the treatment of insomnia: a suitable approach? Drugs 2008; 68: 2411-2417

48 Bond DJ, Hadjipavlou G, Lam RW et al. The Canadian Network for Mood and Anxiety Treatments (CANMAT) task force recommendations for the management of patients with mood disorders and comorbid attention-deficit/hyperactivity disorder. Ann Clin Psychiatry 2012; 24: $23-37$ 